\title{
Mining Simulated Social Network for Personal Problems
}

\author{
S.Benazir \\ M.Phil Research Scholar \\ Alagappa University \\ Karaikudi,India
}

\author{
S.S.Dhenakaran \\ Faculty ,Comp.sci \& Engg. \\ Alagappa University \\ Karaikudi,India
}

\begin{abstract}
In the recent years, Social Network is one of the growing network among different age people.. Social Network is also known as Public Network or Community Network. Social Network is the act of sharing interest, thoughts views, photos, ideas to friends, relatives, colleagues and also can get new friends and gain experiences through the social network in and around the world. In this Paper, one of the social network has been simulated. The combination of medical and legal database has been contributed to the public network. Public network is considered to be "simulated social network" of Facebook. In simulated social network, enable to view all the valid information about the client based upon the criteria mentioned and it connects to linkpages of medical and legal related suggestion of the client. It also make possible for the user to rate the website. Medical pages helps to know about the symptoms, diseases, treatment and specialist for the related disease based upon the client request. Legal pages is used to connect the client who are facing the problem legally and suggests corresponding lawyers related to the problem.
\end{abstract}

\section{Keywords}

Social Network, Facebook, Simulated Social Network, Medical, Legal, Sharing, Rating.

\section{INTRODUCTION}

We The initial Community Network site Six Degrees. com, was launched in 1997. In India, Facebook has been rated as one of the top among the social networking bsites with a user acess of 85 percent . Social networking is the practice of expanding the number of one's business and/or social contacts by making connections through individuals. While social networking has gone on almost as long as societies themselves have existed, the unparalleled potential of the Internet to promote such connections is only now being fully recognized and exploited, through b-based groups established for that purpose [1].The basic aim of this Paper, one of the social network has been simulated. The combination of medical and legal database has been contributed to the public network. Public network is considered to be "simulated social network" of Facebook. In simulated social network, enable to view all the valid information about the client based upon the criteria mentioned. It connects to linkpages of medical and legal related suggestion of the client. It also make possible for the user to rate the bsite. Medical pages helps to know about the symptoms, diseases, treatment and specialist for the related disease based upon the client request. Legal pages is used to connect the client who are facing the problem legally and suggests corresponding lawyers related to the problem.

\section{DATA MINING}

Data mining, also popularly known as Knowledge Discovery in Database, refers to extracting or "mining" knowledge from large amounts of data. Data mining techniques are used to operate on large volumes of data to discover hidden patterns and relationships helpful in decision making [2] .

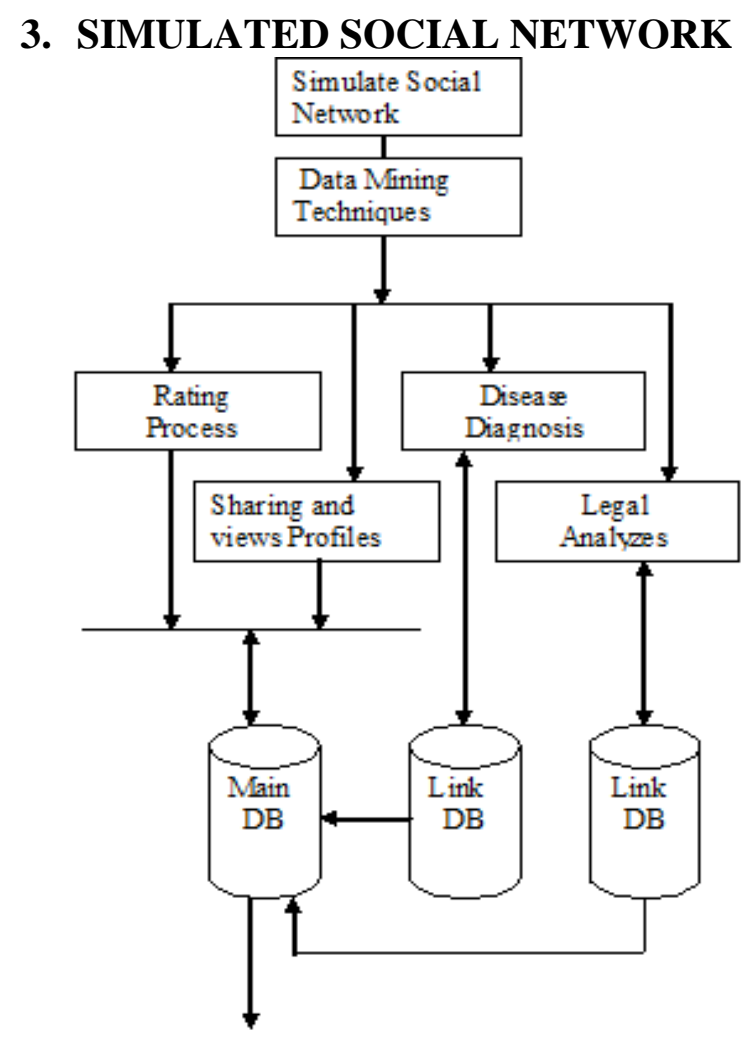

Fig 1: Process of simulated social network

\subsection{Role of Simulated Social Network}

Simulated social network is a replica of a social network. In this paper public network that is Facebook is replicated as a simulated social network. Keeping Facebook social network as a base simulated social network has been designed. The Features of the Facebook has been enhanced by introducing the concept of rating ,sharing, and profile of account holders can be vied by all the user of the site and it connects to linkpages of medical and legal related suggestion for the client based on their request

\subsection{Rating Process}

In rating, the user rates the site. This handles the rating process of the website. There are so many websites around the world which distribute the information given by their owners. It is an effective and easy way to reach the information to the people. There are different types of websites and their pages are with attractive information and design. Rating is a method to know the people mentality about the pages in the website and it also helps the website holder about viewer's response. Fig 1. Shows process of rating system. Here first select the 
category such as education, business, marketing, then rate the such website base upon the user's mentality.

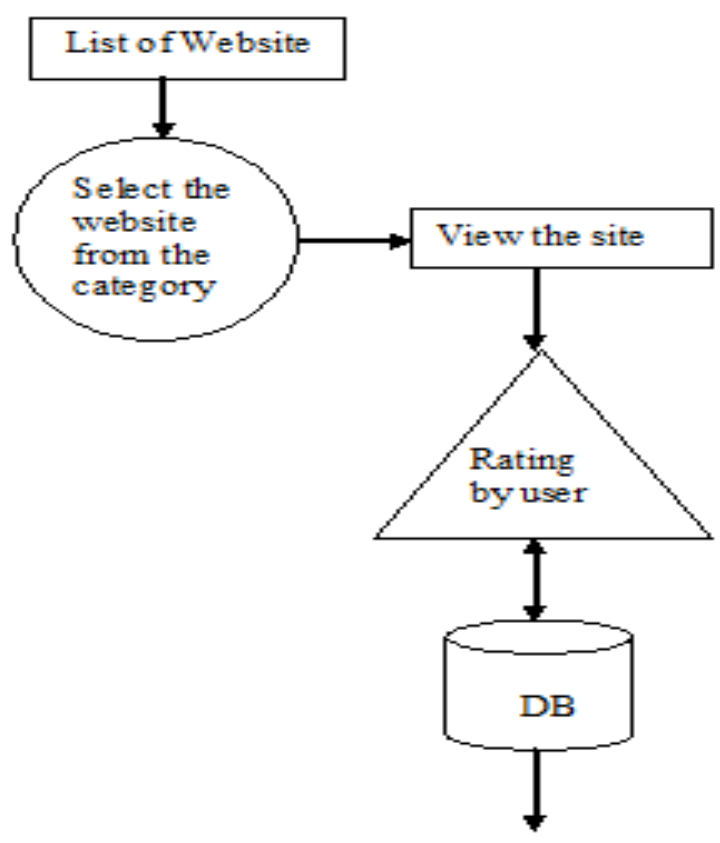

Fig 2: Flow of Rating Process

\subsection{Sharing views and disclosing User's \\ Profile}

In sharing, the people in the list can not only share but also the people in the can view and share the thoughts.

The profile page holds User's Name,Age, Date of birth, Contact Address,Gender, Educational Qualification, Whether working or not, phone number,mail_id, School or College they studied,Proffesion can be accessed .After joining a social network site, users are prompted to identify others in the system with whom they have a relationship. The label for these relationships differs depending on the site-popular terms include "Friends," "Contacts," and "Fans."
Table 1. Simulated Social Data Set

\begin{tabular}{|l|l|l|l|l|l|l|l|l|}
\hline $\begin{array}{l}\text { na } \\
\text { me }\end{array}$ & $\begin{array}{l}\text { ag } \\
\text { gend } \\
\text { er }\end{array}$ & loc & $\begin{array}{l}\text { chil } \\
\mathbf{d}\end{array}$ & $\begin{array}{l}\text { me } \\
\mathbf{d}\end{array}$ & $\begin{array}{l}\text { leg } \\
\text { al }\end{array}$ & $\begin{array}{l}\text { Cnt } \\
\text { ry }\end{array}$ & edu \\
\hline $\begin{array}{l}\text { ban } \\
\text { u }\end{array}$ & 32 & F & $\begin{array}{l}\text { ho } \\
\text { me }\end{array}$ & no & no & yes & india & $\begin{array}{l}\text { em } \\
\text { pl }\end{array}$ \\
\hline john & 27 & M & off & yes & no & yes & usa & stu \\
\hline raja & 30 & M & sch & no & yes & no & india & bus \\
\hline alex & 33 & M & off & yes & yes & no & uk & bus \\
\hline mlol & 22 & F & sch & no & no & yes & uk & stu \\
\hline
\end{tabular}

\subsection{Disease Diagnosis}

Based on the client request Medical pages will be linked by the public network that helps to know about the symptoms, diseases, treatment, observation ,cause for disease and specialist for the related disease . A symptom is a departure from normal function or feeling which is noticed by a patient, indicating the presence of disease or abnormality.A symptom is subjective, observed by the patient, and cannot be measured directly.

Table 2. Sample Specialist

\begin{tabular}{|c|c|c|}
\hline Name & Qualification & Specialization \\
\hline $\begin{array}{l}\text { Dr.Alka } \\
\text { Mandke }\end{array}$ & MD (Anaesthesia) & Anaesthesiology \\
\hline $\begin{array}{l}\text { Dr. Alaric } \\
\text { Aroojis }\end{array}$ & $\begin{array}{l}\text { MBBS, } \\
\text { D'Orthopaedics, } \\
\text { MS } \\
\text { (Orthopaedics), } \\
\text { DNB } \\
\text { (Orthopaedics) }\end{array}$ & $\begin{array}{l}\text { Bone and } \\
\text { Joint / Orthopaedics }\end{array}$ \\
\hline $\begin{array}{l}\text { Dr. Ajay } \\
\text { Mehta }\end{array}$ & $\begin{array}{l}\text { MBBS, } \\
\text { DMRD }\end{array}$ & Radiology \\
\hline $\begin{array}{l}\text { Dr. } \\
\text { Abhishek } \\
\text { Srivastava }\end{array}$ & $\begin{array}{l}\text { MBBS, MD } \\
\text { (Physical } \\
\text { Medicine \& Rehab }\end{array}$ & $\begin{array}{l}\text { Physical Medicine and } \\
\text { Rehabilitation }\end{array}$ \\
\hline
\end{tabular}




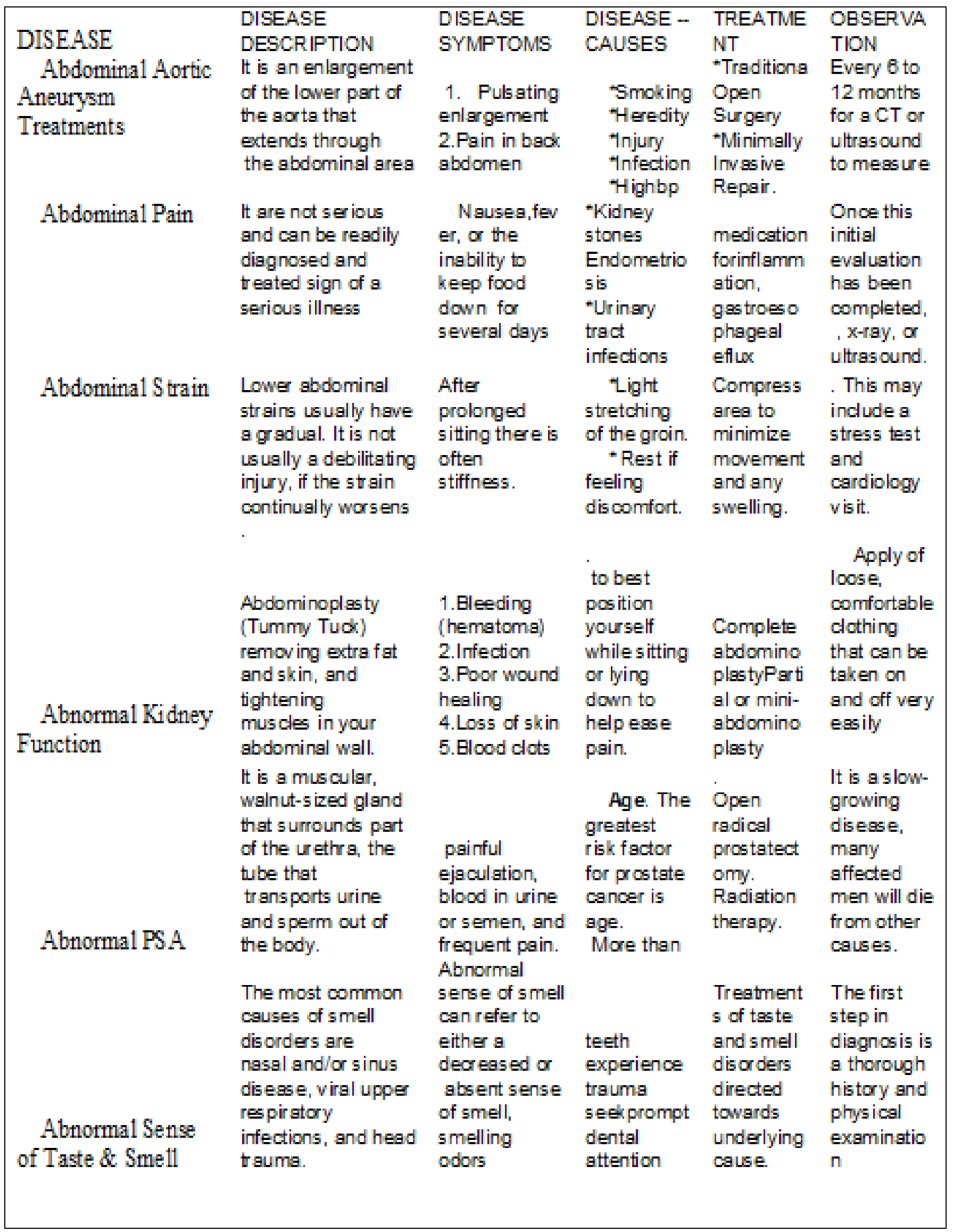




\subsection{Analyzing legal Problem}

Public network links the legal pages if the user's request is of legal one. If the client has a legal problem connects to the legal link.

Table 4. Legal Data Set

\begin{tabular}{|c|c|l|}
\hline Legal Systems & Legal theory & Legal Inst \\
\hline Canon law & Critical legal & Bureaucracy \\
\hline Civil law & Studies & Civil Society \\
\hline Common law & Comparitive law & Election \\
\hline Chinese law & Feminist & Commission \\
\hline Jewish law & Law & Execution \\
\hline Legal pluralism & Economics & Judiciary \\
\hline Roman law & History & Legal \\
\hline Sharia & International & Profession \\
& legal & \\
\hline Socialist law & Theory & Legislature \\
\hline Statutory law & Philosophy & Military \\
\hline Xeer yassa & Sociology & Police \\
\hline
\end{tabular}

Table 4. list out the core subjects ,other subjects, ,sce of law, legal systems, legal theory, legal institution. Simulated social networking can do for lawyers, for their clients and for the legal system, it considers the bad that can result if lawyers improperly or carelessly use social networking sites and services.

\section{EXPERIMENTAL RESULT}

This section presents the experimental results with the simulated social network based on the dataset classification. The results focus to view all the valid information about the client based upon the criteria mentioned and it connects to medical and legal webpage to get suggestions for the clients. It also make possible for the user to rate the site. Medical pages help to know about the symptoms, diseases, treatment and specialist for the related disease based upon the client request. Legal pages are used to connect the client who are facing the problem legally and suggests corresponding lawyers related to their problem.

The following steps are implemented by Simulated Social Network System using data mining techniques using .NET platform .its b-based, user-friendly, scalable, reliable and expandable system. It can also answer complex "what if" queries which usual decision support systems cannot. one of the social network has been simulated. The combination of medical and legal database has been contributed to the public network.

\section{Step 1}

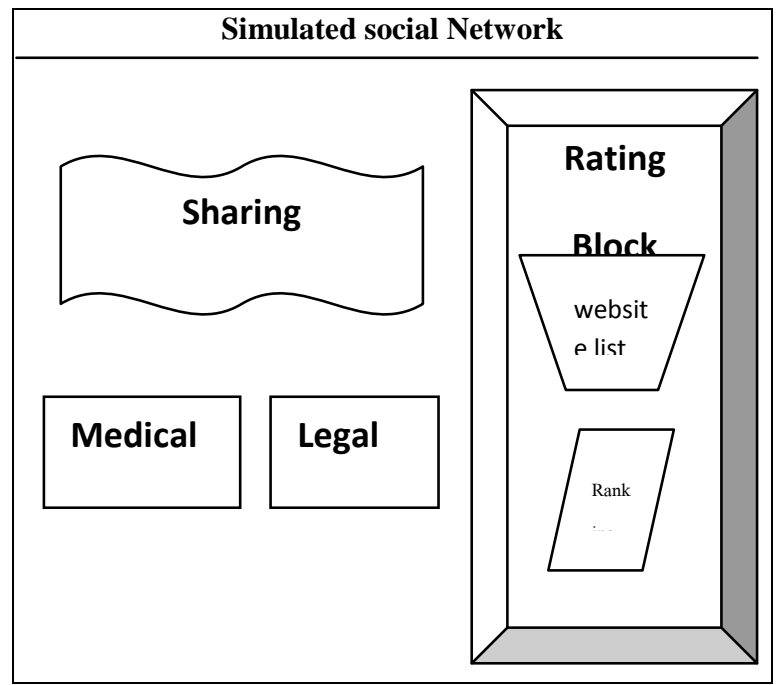

Fig. 4: Main Page

In sharing block, the people in the list can share but also the people in the can view and share the thoughts sharing interest, thoughts views, photos, ideas to friends, relatives, colleagues and also can get new friends and gain experiences through the simulated social network in and around the world.

The profile page holds User's Name,Age, Date of birth, Contact Address,Gender, Educational Qualification, Whether working or not,phone number ,mail_id, School or College they studied ,Proffesion can be accessed.

In Rating block, the user can rate a website by their choice. It can be differ from one user to another user. In this block, the user can select a website by client or by the category placed by the admin of the website. The user can rate the website for client choice. Rank plays the main role to select which website is best. With Advanced Web Ranking you can generate highly customizable main webpage for any search engine and keyword combination. The goal that has been achieved by this Rating block system includes. Simplifies the Appointment Operation ,Decision making is quickly to show the top rated websites along their rank., It reduces time and increase productivity., User friendly screens to enter the data.

In Medical block, to provide know about the symptoms, diseases, treatment and specialist for the related disease based upon the client request. First to click medical block and view medical page. The following steps are give to know about the full description of related and also to give symptoms treatment, reason an also observation of such disease and also to direct the specialist medicinal region. 
Step 2

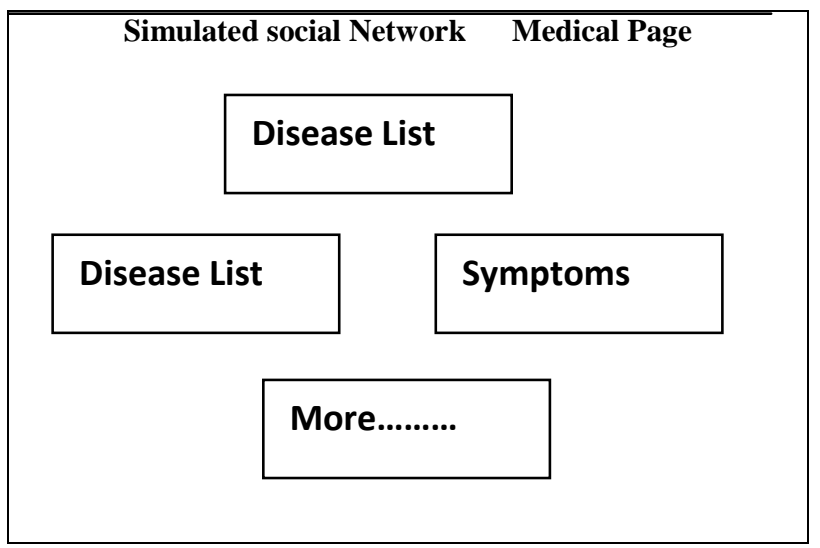

Fig. 5: Medical Page

Figure 5. to show Disease List, disease symptoms, disease description and more option. Disease List to provide 1000's of disease set and user select any disease to show disease description and also to give symptoms of disease based upon the client request .

Figure 6 shows client select the disease from disease set list box and to view two dialog box first to show Disese Description and second to show Disease Symptoms .

Step 3

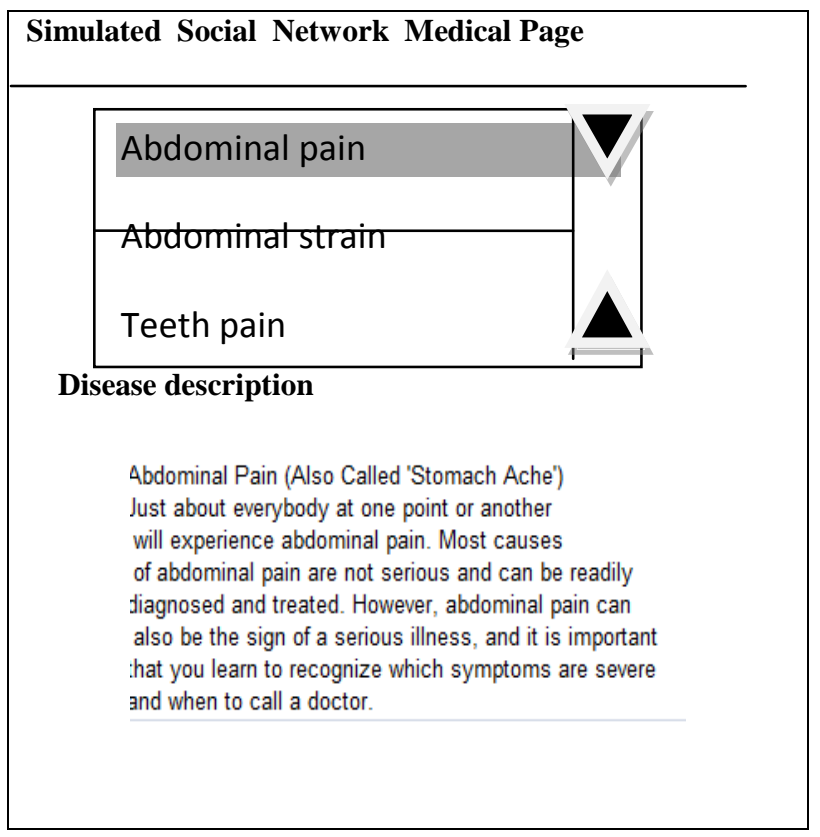

Fig. 6 Example for Disease list and their symptoms
Step 4

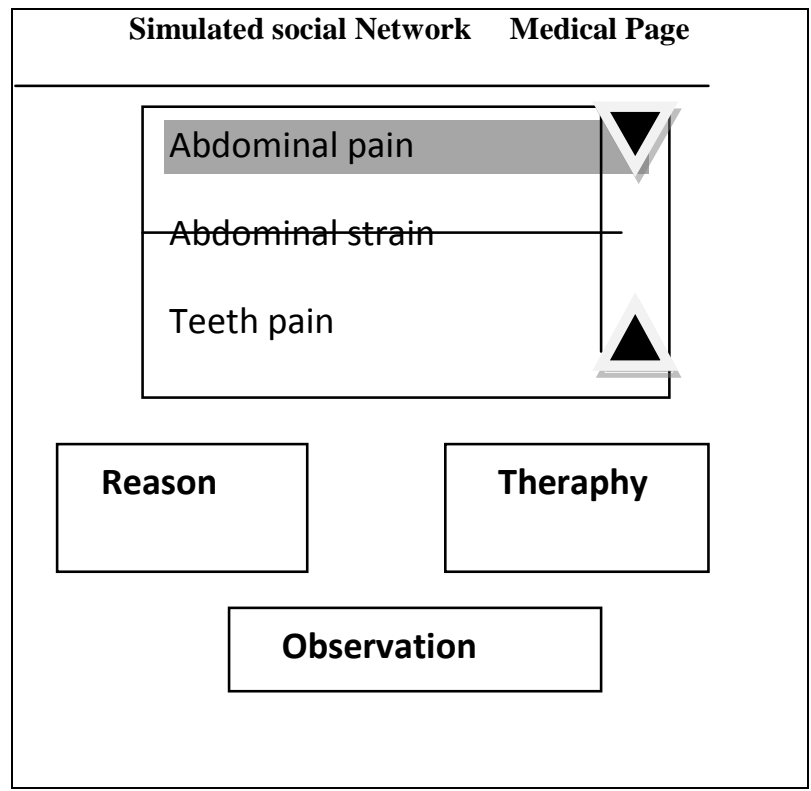

Fig. 7: Disease list and their

Treatment,reason,observation

Figure 7 shows Disease List and their treatment, reason, observation pedestal ahead the user's request. Finally More option to get a direction for specialist based upon the specialization.

In Legal page, pages if the user's request is of legal one.If the client has a legal problem connects to the legal link. and to connect the client who are facing the problem legally and suggests corresponding lawyers related to the problem.

Example 1

\begin{tabular}{|l|l|l|}
\hline Name & Specialization & Office name \\
\hline $\begin{array}{l}\text { Ashish } \\
\text { Ahuja }\end{array}$ & $\begin{array}{l}\text { Commercial } \\
\text { law }\end{array}$ & Wadia Ghandy \& Co \\
\hline $\begin{array}{l}\text { Balbir } \\
\text { Singh }\end{array}$ & Criminal law & DSK Legal \\
\hline $\begin{array}{l}\text { Gayatri } \\
\text { Roy }\end{array}$ & $\begin{array}{l}\text { Administrative } \\
\text { law }\end{array}$ & Luthra \& Luthra \\
\hline $\begin{array}{l}\text { Gunjan } \\
\text { Paharia }\end{array}$ & Military law & ZeusIP \\
\hline
\end{tabular}


Example 2

\begin{tabular}{|l|l|}
\hline Administrative law & Admiralty law \\
Constitutional law & Agricultural law \\
Criminal law & Aviation law \\
Equity & Banking law \\
Evidence & Bankruptcy \\
Law of obligations & Commercial law \\
Procedure & Companies law \\
Civil & Conflict of laws \\
Criminal & Construction law \\
Property law & Consumer protection \\
& Cyberlaw \\
\hline
\end{tabular}

Example 1 and example 2 shows list of cases and lawyers set .User's select the case that is criminal case or civil case etc then it shows the appropriate lawyers name and office name.

The experimental result to show that by using data mining techniques become easier hence verification also be tested.

\section{CONCLUSIONS}

The Proposed article mining information to the users of simulated social network. It is implemented with the support of Medical dataset and Legal dataset to give response to the mining process of users. A sample dataset is used for experimentation for testing purpose. It concluded that the development of such a system helps user to get easy direction for their problems.

\section{REFERENCES}

[1] IJCSNS, Rising of Social Network bsites in India Overview Ateeq Ahmad Department of Computer science \& Engineering .

[2] International Jnal of Computer Science and Network (IJCSN)Classification of Student's data Using Data Mining Techniques for Training \& Placement 1Samrat singh,2Dr.VikeshKumar.

[3] Social Network Sites: Definition, History, and Scholarship danah m. boyd mb@ischool.berkeley.eduSchool of Information University of California-Berkeley. 